\title{
Metode Absensi Mahasiswa Berbasis QR Code dan Time-Based One-Time Password
}

\author{
Aprianti Nanda Sari ${ }^{1}$, Trisna Gelar Abdillah ${ }^{2}$ \\ 1,2 Jurusan Teknik Komputer, Politeknik Negeri Bandung, Indonesia \\ ${ }^{1}$ aprianti.nanda@polban.ac.id, ${ }^{2}$ trisna.gelar@polban.ac.id
}

\begin{abstract}
Abstrak
Sistem absensi manual dengan cara memanggil nama mahasiswa satu persatu oleh dosen atau dengan menandatangani list kehadiran tentunya akan memakan waktu yang cukup lama dan tidak aman. Maka dibangunlah sistem absensi terkomputerisasi berbasis sidik jari, RFID, pengenalan wajah dan lainnya. Akan tetapi metode-metode tersebut memerlukan biaya tambahan untuk membeli alat khusus. Sebagai solusi, akhirnya sistem absensi berbasis $Q R$ code semakin diminati karena hanya memerlukan webcam bawaan dari laptop atau PC, atau kamera smartphone. Mahasiswa yang hadir di kelas hanya butuh memindai $Q R$ code yang tertera pada saat kelas berlangsung melalui smartphone mereka sebagai tanda kehadiran. Akan tetapi sistem absensi berbasis $Q R$ code ini memiliki celah misalnya mahasiswa yang hadir dapat mengambil gambar dan mengirimkan $Q R$ code di kelas kepada temannya yang tidak hadir agar dapat dianggap hadir. Sehingga diperlukan sistem autentikasi dengan keamanan tambahan agar kecurangan pada sistem absensi berbasis $Q R$ code tidak terjadi. Salah satu upayanya adalah dengan menggunakan One-Time Password yang dibuat unik dan dinamis untuk setiap mahasiswa dan hanya berlaku sekali saja dalam waktu singkat saja atau yang lebih dikenal sebagai Time-based One-Time Password atau disingkat TOTP. Dari hasil analisa, penggunaan TOTP dapat menghindari berbagai kemungkinan kecurangan oleh mahasiswa dan penyerangan oleh pihak ketiga.
\end{abstract}

Kata kunci : sistem absensi mahasiswa, QR code, one-time password, time-based one-time password, TOTP

\section{Pendahuluan}

Sistem absensi merupakan hal penting dalam berlangsungnya kegiatan belajar mengajar di perguruan tinggi terutama bagi mahasiswa. Di sebagian perguruan tinggi, sistem absensi masih menggunakan tanda tangan. Hal ini tentunya tidak praktis karena rekap kehadiran mahasiswa harus dilakukan secara manual.Untuk itu beberapa sistem absensi terkomputerisasi dibangun dengan berbagai metode seperti sidik jari, RFID, pengenalan wajah (face recognition) dan masih banyak lainnya. Namun metode-metode tersebut memakan biaya tambahan karena memerlukan alat khusus.

Sebagai solusi untuk membangun sistem absensi yang minim biaya, beberapa sistem absensi yang sudah dibangun memanfaatkan $Q R$ Code. Selain tidak membutuhkan biaya karena bisa menggunakan kamera smartphone atau webcam sebagai pemindai, $Q R$ Code mudah diimplementasikan dan tidak membutuhkan sistem komputasi yang rumit. Beberapa sistem absensi berbasis $Q R$ Code yang sudah dibangun adalah oleh Nuddin, et al (2015), Ardhianto (2016), Aini, et al (2017), Hermanto, et al (2019), dan Pujastuti et al (2020). Akan tetapi sistem absensi berbasis $Q R$ Code ini juga masih memiliki celah. Misalnya, mahasiswa yang hadir di kelas dapat mengambil foto $Q R$ Code yang ada di kelas kemudian mengirimkannya ke mahasiswa lain yang tidak hadir sehingga dapat dianggap hadir. Untuk itu, diperlukan sistem absensi berbasis $Q R$ Code yang aman sehingga mengurangi kemungkinan terjadinya kecurangan dalam sistem absensi.

Salah satu cara untuk menghindari kecurangan tersebut adalah dengan penggunaan password dinamis atau yang lebih dikenal sebagai One-Time Password (OTP) ((Lamport, 1981), (Babkin et al, 2019), (Liao et al, 2009), dan (Malik et al, 2014)). Pada penelitian ini, OTP berbasis waktu (Time-based One-Time Password) atau yang dikenal sebagai TOTP digunakan karena password hanya berlaku pada rentang waktu yang singkat. Hal ini bertujuan agar mahasiswa tidak melakukan kecurangan seperti mengirimkan $Q R$ Code tidak memiliki waktu yang cukup.

\section{Landasan Teori}

Pada bab ini, teori dasar mengenai $Q R$ Code, TOTP dibahas secara singkat

\subsection{QR Code}

QR Code atau Quick Response Code merupakan bentuk dua dimensi dari barcode. $Q R$ Code pertama kali dikenalkan oleh Denso Wave pada tahun 1994 (Soon, 2008), (Hanks, 2012), (Singh et al 2016). Seiring berkembangnya teknologi, saat ini $Q R$ Code tidak hanya dikenali dan dibaca melalui pemindai 
khusus tetapi kamera pada smartphone, bahkan webcam. Biasanya $Q R$ Code berisi informasi seperti teks, link URL, geo-location, nomor telepon, kartu nama, dan hal lainnya yang dapat disematkan. $Q R$ Code terlihat seperti sebuah kotak kecil berisi piksel berwarna hitam dan putih yang ditempatkan secara acak seperti pada Gambar 1 .

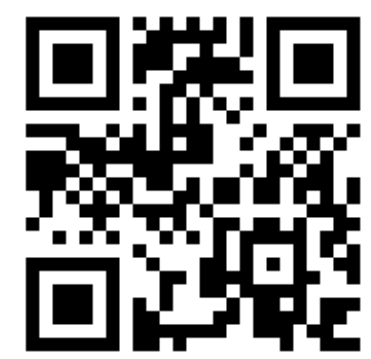

Gambar 1 Contoh QR Code

\subsection{Time-based One-Time Password}

One-Time Password (OTP) merupakan serangkaian symbol atau angka yang dibuat sebagai password dan digunakan satu kali saja. Salah satu penggunaan OTP adalah untuk autentikasi pengguna, misalnya pada media sosial, online banking, maupun dompet digital.

Ada banyak algoritma untuk membangkitkan OTP, salah satunya adalah Time-based One-Time Password (TOTP). Menurut M'Raihi, et.al (2011), cara kerja TOTP adalah membuat password berdasarkan kunci dan waktu saat algoritma TOTP digunakan. Secara umum, TOTP memiliki skema yang sama dengan HMAC-based One-Time Password atau HOTP, namun yang membedakan adalah proses perhitungannya melibatkan kunci dan waktu sehingga TOTP dapat dinotasikan sebagai persamaan (1). Di mana $K$ adalah kunci yang bersifat acak (random) dan $T$ adalah waktu.

$$
\text { TOTP }=\operatorname{HOTP}(K, T)
$$

Nilai dari $T$ dihitung berdasarkan persamaan (2). Di mana $T_{\text {current }}$ adalah waktu saat ini dalam satuan detik, $T_{0}$ adalah waktu inisiasi yang disepakati biasanya bernilai $0\left(T_{0}=0\right)$. Sedangkan $v$ adalah parameter yang menentukan berapa lama sebuah TOTP valid. Biasanya $v=30$ sehingga TOTP hanya valid dalam waktu 30 detik.

$$
T=\frac{T_{\text {current }}-T_{0}}{v}
$$

\section{Metode Penelitian}

Penelitian ini terdiri dari empat tahap utama yaitu studi literatur, perancangan fungsional sistem, pembuatan purwarupa, serta pengujian dan analisa hasil purwarupa. Studi literatur bertujuan untuk mengumpulkan sumber literasi dan menganalisa permasalahan yang ada pada sistem absensi berbasis QR Code yang sudah dibahas pada Bab 2. Pada tahap perancangan, bertujuan untuk membuat gambaran awal dari metode yang diajukan. Setelah dirancang, maka dilanjutkan dengan implementasi berupa pembuatan purwarupa yang kemudian diuji dan dianalisa.

Sistem absensi mahasiswa yang dibangun terdiri dari dua modul yaitu modul server dan modul smartphone yang memiliki fungsi berbeda. Modul server yang dibangun adalah berbasis web dan digunakan oleh staf administrasi kampus dan dosen untuk mengelola data mahasiswa, kelas, dan dosen. Selain itu, modul server juga berfungsi sebagai pembangkit TOTP, pemindai $Q R$ Code, serta merekap kehadiran mahasiswa. Modul server hanya dapat diakses oleh jaringan lokal, sehingga hanya staf administrasi kampus dan dosen yang dapat mengakses.

Modul smartphone diinstall dan digunakan oleh mahasiswa untuk mengecek jadwal kuliah, penampil $Q R$ code berisi identitas diri, serta penampil $Q R$ Code berisi TOTP yang berlaku sebagai tanda kehadiran.

Sistem ini terdiri dari dua prosedur utama yaitu prosedur registrasi dan prosedur verfikasi. Terdapat beberapa notasi yang digunakan pada tulisan ini seperti yang dijelaskan pada Tabel 1 .

Tabel 1 Notasi persamaan yang digunakan

\begin{tabular}{|c|l|}
\hline Notasi & \multicolumn{1}{|c|}{ Keterangan } \\
\hline$h(a)$ & $\begin{array}{l}\text { Fungsi hash satu arah dari parameter } \\
\text { bernama } a .\end{array}$ \\
\hline$E_{Q R}(a)$ & $\begin{array}{l}\text { Fungsi untuk mengubah parameter } a \\
\text { menjadi } Q R \text { Code }\end{array}$ \\
\hline$D_{Q R}(a)$ & $\begin{array}{l}\text { Fungsi untuk mengubah QR code } \\
\text { bernama } a \text { menjadi link autofilled }\end{array}$ \\
\hline$a \oplus b$ & Operasi XOR antara $a$ dan $b$ \\
\hline$L(a)$ & Membuat link sesuai parameter $a$ \\
\hline$I D_{S}$ & ID dari sesi kuliah berjalan \\
\hline$N I M$ & Nomor Induk Mahasiswa \\
\hline$I M E I$ & $\begin{array}{l}\text { International Mobile Equipment } \\
\text { Identity dari smartphone mahasiswa }\end{array}$ \\
\hline
\end{tabular}

\subsection{Prosedur Registrasi}

Tujuan dari prosedur registrasi adalah mengumpulkan data mahasiswa beserta identitas smartphone yang digunakan seperti pada Gambar 2 dengan rincian sebagai berikut.

- Langkah 1: Modul server yang dioperasikan oleh staf administrasi kampus akan meminta dan menyimpan identitas mahasiswa dan identitas smartphone yang digunakan. Identitas ini haruslah unik seperti NIM dan IMEI (International Mobile Equipment Identity).

- Langkah 2: Modul server akan menghitung nilai hash $(x)$ dari NIM dan IMEI mahasiswa dengan menggunakan persamaan (3):

$$
x=h(N I M \oplus I M E I)
$$




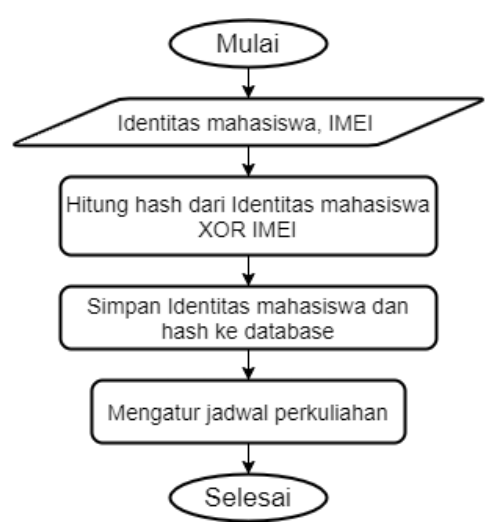

Gambar 2 Prosedur registrasi

- Langkah 3: Modul server akan menyimpan nilai $x$ bukan IMEI

- Langkah 4: Staf administrasi kampus akan mengatur jadwal perkuliahan dan identitas mahasiswa yang mengikuti perkuliahan tersebut.

\subsection{Prosedur Verifikasi}

Prosedur verifikasi dilakukan saat mahasiswa mencatatkan kehadirannya pada saat perkuliahan. Prosedur verifikasi secara garis besar dapat dilihat pada Gambar 3 yang memiliki rincian sebagai berikut.

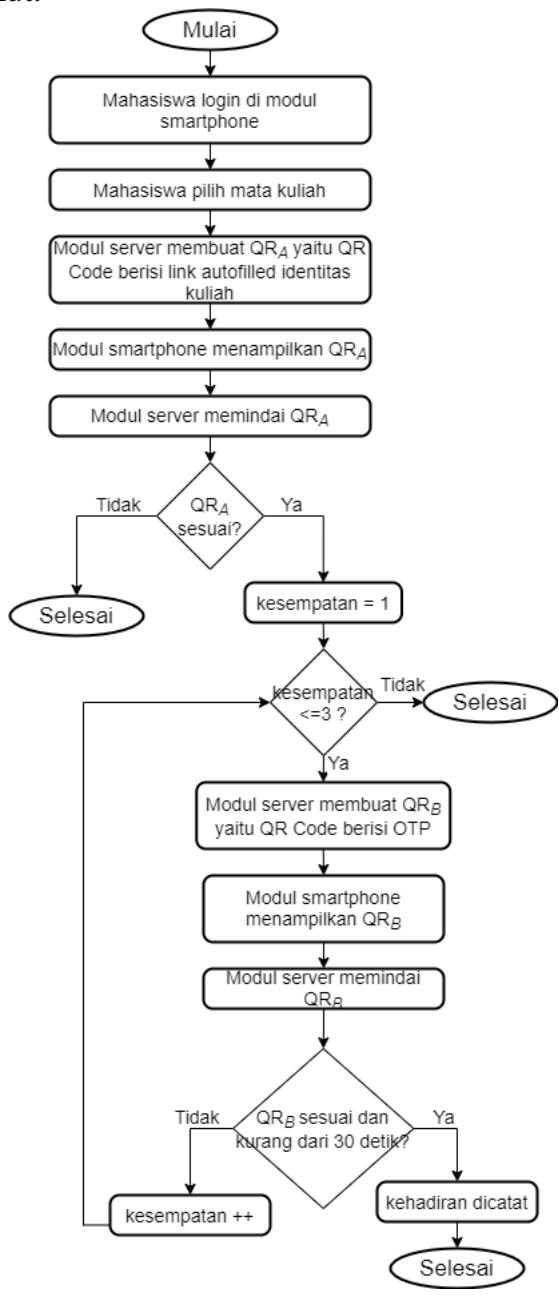

Gambar 3 Prosedur verifikasi
- Langkah 1: sebelum masuk kelas, mahasiswa membuka modul smartphone yang terlebih dahulu diinstall.

- Langkah 2: mahasiswa login pada modul smartphone dengan menginputkan username yang berupa NIM dan password.

- Langkah 3: mahasiswa akan diberikan list jadwal sesi kuliah pada hari ini.

- Langkah 4: modul server akan membuat link unik yang bersifat autofilled berisi identitas sesi kuliah, mahasiswa, dan smartphone. Link ini dinotasikan sebagai $L_{a}$ berdasarkan persamaan (4).

$$
L_{a}=\left(I D_{S}, N I M, I M E I\right)
$$

- Langkah 5: modul smartphone akan mengumpulkan identitas sesi kuliah yang dipilih, identitas mahasiswa, dan identitas smartphone yang digunakan secara otomatis

- Langkah 6: modul smartphone memodifikasi $L_{a}$ menjadi $L_{a}{ }^{\prime}$ sesuai data yang diperoleh di Langkah 6. Kemudian mengakses link $L_{a}{ }^{\prime}$ yang merupakan link autofilled.

- Langkah 7: modul smartphone akan membuat QR code berisi link $L_{a}{ }^{\prime}$ dan menampilkannya di layar

$$
Q R_{1}=E_{Q R}\left(L_{a}{ }^{\prime}\right)
$$

- Langkah 8: modul server kemudian memindai $Q R_{1}$ dan mengubahnya menjadi link $L_{a}{ }^{\prime}$

$$
L_{a}{ }^{\prime}=D_{Q R}\left(Q R_{1}\right)
$$

- Langkah 9: berdasarkan data sesi kuliah dan NIM yang dikirim pada Langkah 6, modul server akan mencocokan data dari $L_{a}{ }^{\prime}$ yang diberikan dengan daftar mahasiswa yang mengikuti sesi kuliah tersebut. Jika data tidak cocok, maka modul smartphone dan server akan memberikan peringatan bahwa mahasiswa tersebut tidak terdaftar pada sesi kuliah, kemudian prosedur verifikasi selesai. Jika data cocok, maka modul server akan menghitung nilai hash $y$ seperti pada persamaan (7). Tujuannya untuk memastikan apakah mahasiswa tersebut menggunakan smartphone miliknya.

$$
y=h(N I M \oplus I M E I)
$$

- Langkah 10: modul server akan mencocokan apakah $y$ memiliki nilai yang sama dengan $x$ pada Prosedur Registrasi. Jika nilai $x$ tidak sama $y$ maka modul smartphone akan memberikan peringatan bahwa mahasiswa harus menggunakan smartphone dengan IMEI yang terdaftar kemudian prosedur verifikasi selesai. Jika $x$ dan $y$ identik, maka proses dilanjutkan ke Langkah 11. Langkah pencocokan identitas ini dilakukan sebagai pemicu agar modul server tidak membuat password dinamis TOTP setiap waktu dan hanya dilakukan jika mahasiswa benar-benar teridentifikasi dan berada di dekat komputer kelas yang terhubung dengan modul server. 
- Langkah 11: modul server akan membuat password dinamis TOTP yang hanya berlaku 30 detik saja seperti pada persamaan (1) dan (2) dengan nilai $v=30$

- Langkah 12: modul server akan menghitung nilai hash dari IMEI smartphone mahasiswa (yang dihasilkan dari Langkah 6) dan TOTP yang dihasilkan kemudian menyimpannya sebagai $r$ berdasarkan fungsi berikut.

$$
r=h(I M E I \oplus T O T P)
$$

- Langkah 13: modul server akan membuat link yang bersifat autofilled berisi nilai hash IMEI dan TOTP. Link ini dinotasikan sebagai $L_{b}$ berdasarkan fungsi berikut.

$$
L_{b}=(r)
$$

- Langkah 14: modul smartphone akan membuat QR Code berisi link $L_{b}$ berdasarkan persamaan (9) dan menampilkannya di layar.

$$
Q R_{2}=E_{Q R}\left(L_{b}\right)
$$

- Langkah 15: modul server kemudian memindai $Q R_{2}$ dan mengubahnya menjadi link $L_{b}$ dan mengakses link tersebut

$$
L_{b}=D_{Q R}\left(Q R_{2}\right)
$$

- Langkah 16: modul server akan mengevaluasi nilai hash dari IMEI dan TOTP yang diberikan, nilai hash ini dinotasikan sebagai $s$

- Langkah 17: modul server akan mencocokan nilai $r$ pada Langkah 12 dan $s$ pada Langkah 16. Jika $r$ dan $s$ identik, maka kehadiran mahasiswa dicatat. Jika tidak identik, maka kembali ke Langkah 11. Jika Langkah 11 sudah dilakukan tiga kali (mahasiswa sudah mencoba memindai QR code berisi TOTP sebanyak tiga kali), maka proses verifikasi terhenti dan mahasiswa dianggap tidak hadir.

- Langkah 18: pada akhir sesi kuliah, dosen dapat mengakses modul server diberi kesempatan untuk mengecek ulang kehadiran mahasiswa di kelasnya.

\section{Implementasi}

Sistem yang sudah dirancang, akan diimplementasikan dalam sebuah purwarupa sistem. Berikut adalah tampilan purwarupa sistem.

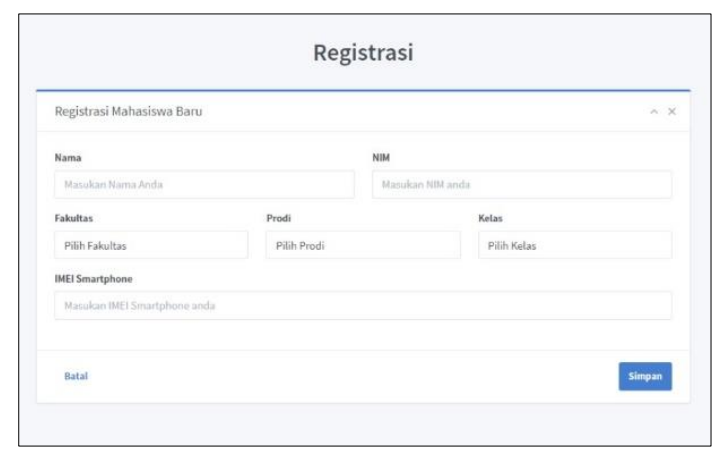

Gambar 4 Registrasi
Gambar 3 adalah tampilan modul server saat prosedur registrasi. Pada Gambar 4, modul smartphone menampilkan jadwal mahasiswa pada hari ini. Setelah memilih kelas, maka akan tampil $Q R$ Code berisi link autofilled identitas kelas yang dipilih seperti pada Gambar 5. QR Code tersebut hanya berlaku pada saat jadwal perkuliahan di mulai.

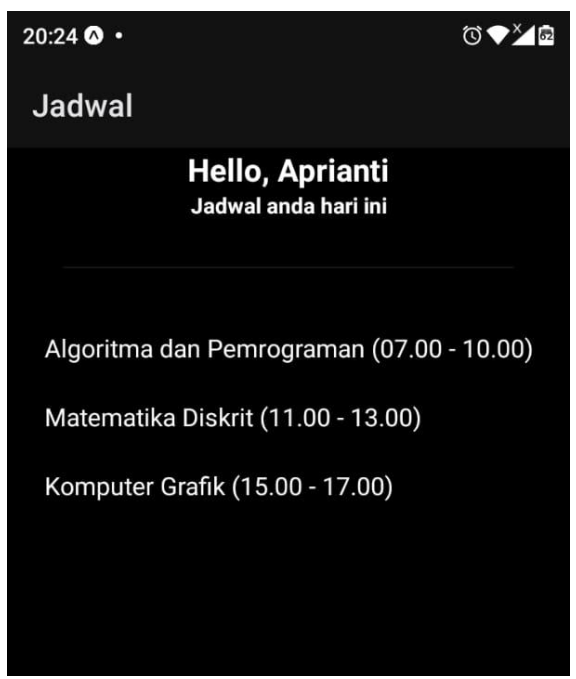

Gambar 5 Modul smartphone menampilkan jadwal kuliah

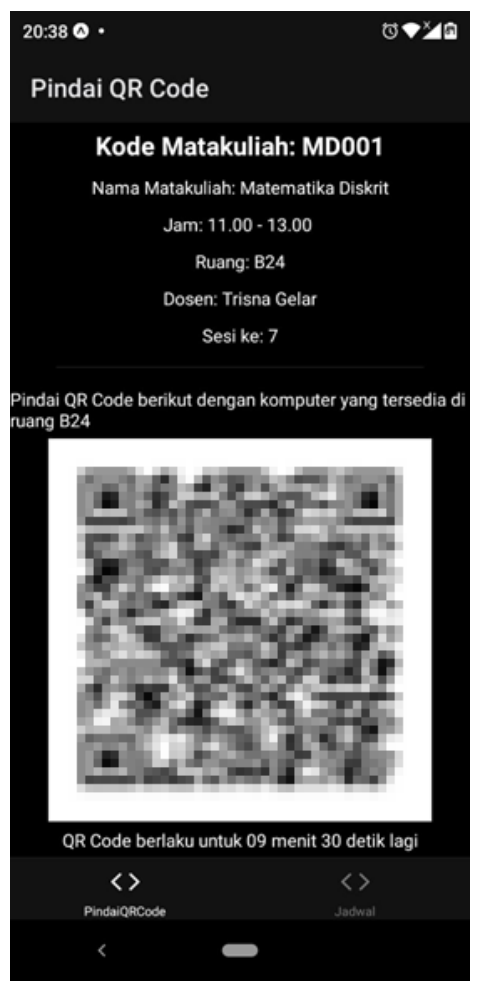

Gambar 6 Modul smartphone menampilkan QR Code berisi identitas kuliah 


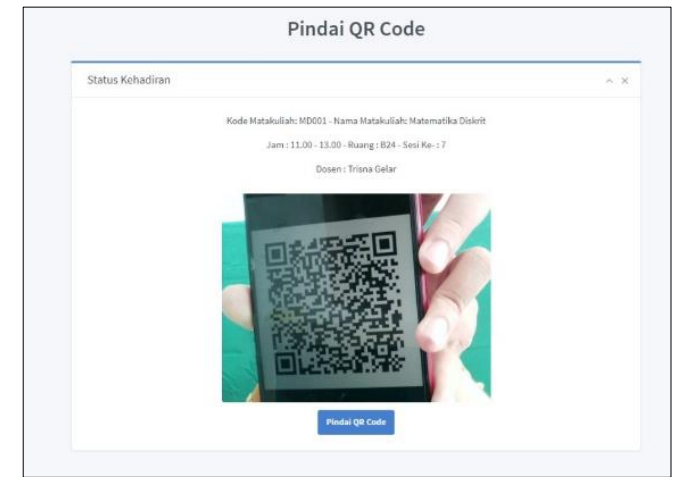

Gambar 7 Modul server memindai QR Code berisi identitas kuliah

Modul server kemudian akan memindai $Q R$ Code berisi link autofilled identitas kelas seperti pada Gambar 6. Jika sesuai, maka modul smartphone akan menampilkan $Q R$ Code berisi TOTP seperti pada Gambar 7.

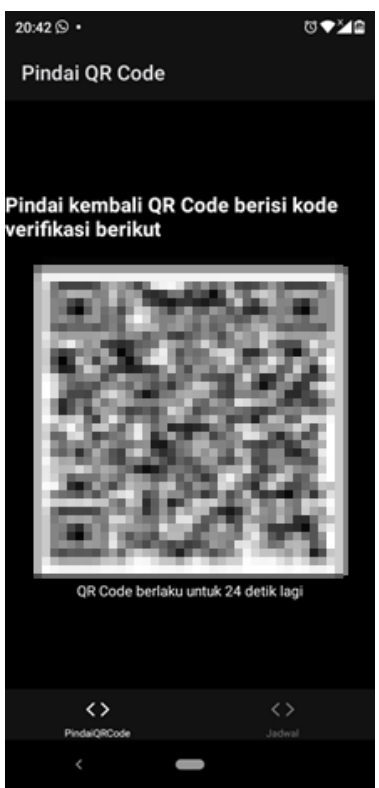

Gambar 8 Modul smartphone menapilkan QR Code berisi TOTP

Setelah itu, modul server akan memindai QR Code berisi TOTP seperti pada Gambar 8. Jika sesuai, maka kehadiran mahasiswa akan dicatat seperti pada Gambar 9.

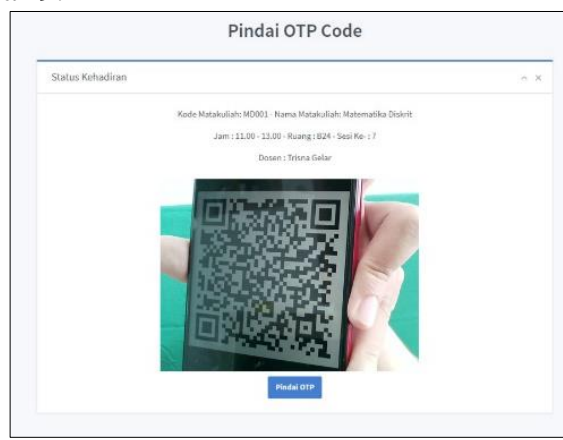

Gambar 9 Modul server memindai QR Code berisi OTP

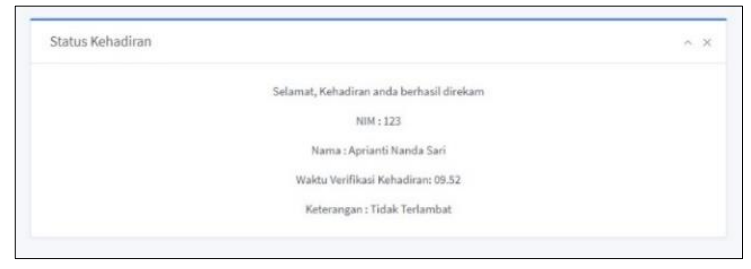

Gambar 10 Kehadiran mahasiswa berhasil dicatat

\section{Pengujian dan Analisa}

Pada bab ini akan dibahas mengenai pengujian terhadap fungsionalitas sistem serta analisa keamanan.

\subsection{Pengujian Blackbox}

Pengujian blackbox hanya bertujuan menjaga fungsionalitas sistem tanpa memperhatikan detailnya.

Tabel 2 Pengujian blackbox prosedur registrasi

\begin{tabular}{|c|l|c|}
\hline No & \multicolumn{1}{|c|}{ Pengujian } & Hasil \\
\hline 1 & Input identitas mahasiswa & Berhasil \\
\hline 2 & Input IMEI & Berhasil \\
\hline 3 & Menghitung nilai hash & Berhasil \\
\hline 4 & Menyimpan identitas mahasiswa & Berhasil \\
\hline 5 & Menyimpan nilai hash & Berhasil \\
\hline
\end{tabular}

Tabel 3 Pengujian blackbox prosedur verifikasi

\begin{tabular}{|c|l|c|}
\hline No & \multicolumn{1}{|c|}{ Pengujian } & Hasil \\
\hline 1 & $\begin{array}{l}\text { Modul server membuat } \mathrm{QR}_{\mathrm{A}}(Q R \\
\text { Code berisi link autofilled } \\
\text { identitas kuliah) }\end{array}$ & Berhasil \\
\hline 2 & $\begin{array}{l}\text { Modul smartphone menapilkan } \\
\mathrm{QR}_{\mathrm{A}}\end{array}$ & Berhasil \\
\hline 3 & ${\text { Modul server memindai } \mathrm{QR}_{\mathrm{A}}}$ & Berhasil \\
\hline 4 & $\begin{array}{l}\text { Modul server mengecek apakah } \\
\text { QR } \text { sesuai dengan jadwal }\end{array}$ & Berhasil \\
\hline 5 & $\begin{array}{l}\text { Modul server membuat } \mathrm{QR}_{\mathrm{B}}(Q R \\
\text { Code berisi TOTP) }\end{array}$ & Berhasil \\
\hline 6 & $\begin{array}{l}\text { Modul smartphone menapilkan } \\
\text { QR }\end{array}$ & Berhasil \\
\hline 7 & $\begin{array}{l}\text { Modul server memindai QR } \\
\mathrm{B}\end{array}$ & Berhasil \\
\hline 8 & $\begin{array}{l}\text { Modul server mengecek apakah } \\
\text { QR } \\
\text { (tidak lebuai dan masih berlaku }\end{array}$ & Berhasil \\
\hline
\end{tabular}

\subsection{Analisa Keamanan}

Analisa keamanan bertujuan untuk mengetahui kemungkinan penyerangan yang dilakukan.

\subsubsection{Penyerangan Terhadap IMEI Smartphone}

Jika seseorang dapat menebak IMEI smartphone yang mahasiswa gunakan, maka ada kemungkinan ia juga bisa memodifikasi TOTP pada tahap verifikasi Langkah 10. Akan tetapi, hal ini sulit dilakukan karena IMEI yang disimpan dalam bentuk hash sesuai dengan persamaan (3). Seperti yang kita 
ketahui bahwa hash adalah sebuah fungsi satu arah sehingga tidak bisa dipecahkan (Singh \& Garg 2009).

\subsubsection{Man-in-the-middle attack}

Man-in-the-middle attack adalah sebuah istilah yang menggambarkan pihak ketiga yang mencoba memposisikan diri atau berpura-pura menjadi pengguna dari sebuah sistem. Tujuannya adalah untuk memata-matai atau berpura-pura menjadi pihak lain sehingga terjadi pertukaran informasi yang dirahasiakan (Mallik et al, 2019).

Dalam kasus ini, misalnya seorang penyelundup mencoba menyadap ketika modul server dan modul smartphone bertukar informasi mengenai TOTP pada prosedur verifikasi langkah 15 . Akan tetapi, hal ini tidak mungkin terjadi karena $Q R$ Code yang berisi TOTP sudah berupa hash sesuai persamaan (7).

\section{Kesimpulan dan Saran}

Berdasarkan hasil pengujian blackbox, sistem ini berhasil bekerja secara fungsional. Selain itu, dengan penggunaan TOTP pada penelitian ini, kecurangan mahasiswa yang mengambil gambar $Q R$ Code dan memberikannya pada mahasiswa yang tidak hadir dapat dihindari karena penggunaan $Q R$ Code yang bersifat dinamis dan TOTP yang hanya berlaku dalam waktu singkat. Selain itu, kemungkinan mahasiswa meminjam smartphone temannya untuk absen juga dapat dihindari karena sistem absesni ini hanya dapat diakses oleh mahasiswa yang IMEI smartphone-nya terdaftar.

Tidak hanya itu, berdasarkan analisa keamanan penggunaan hash untuk menyimpan identitas mahasiswa dan smartphone juga dapat menghindari penyerangan terhadap IMEI dan metode penyerangan man-in-the-middle attack.

Karena sistem ini masih berupa purwarupa, maka penulis menyarankan untuk melanjutkan pengembangan sistem yang lebih kompleks dan sesuai dengan standar prosedur absensi di perguruan tinggi.

\section{Daftar Pustaka:}

Aini, Q., Graha, Y. I., \& Zuliana, S. R. (2017). Penerapan Absensi QRCode Mahasiswa Bimbingan Belajar pada Website berbasis YII Framework. Sisfotenika, 7(2), 207-218.

Ardhianto, E. (2016). Mesin Presensi Cepat Dengan Menggunakaqr Code Dan Webcam. Jurnal Informatika Upgris, 2(2).

Babkin, S., \& Epishkina, A. (2019, January). Authentication Protocols Based on One-Time Passwords. In 2019 IEEE Conference of Russian Young Researchers in Electrical and Electronic Engineering (EIConRus) (pp. 1794-1798). IEEE.

Hanks, H. "Successful Scanning: A Guide to QR Code Best Practices." (2012): 1-18.

Hermanto, N., \& Riyanto, N. R. D. R. (2019). Aplikasi sistem presensi mahasiswa berbasis android. Simetris: Jurnal Teknik Mesin, Elektro dan Ilmu Komputer, 10(1), 107-116.

Liao, K. C., Lee, W. H., Sung, M. H., \& Lin, T. C. (2009, August). A one-time password scheme with QR-code based on mobile phone. In 2009 Fifth International Joint Conference on INC, IMS and IDC (pp. 2069-2071). IEEE.

Lamport, L. (1981). Password authentication with insecure communication. Communications of the ACM, 24(11), 770-772.

Mallik, A. (2019). Man-in-the-middle-attack: Understanding in simple words. International Journal of Data and Network Science 3(2): 7792.

Malik, J., Girdhar, D., Dahiya, R., \& Sainarayanan, G. (2014). Multifactor Authentication Using a QR Code and a One-Time Password. JIPS, 10(3), 483.

M'Raihi, D., Machani, S., Pei, M., \& Rydell, J. (2011). Totp: Time-based one-time password algorithm. Internet Engineering Task Force, May 2011

Nuddin, Mukhamad Taqwa, and Diana Laily Fithri. "Sistem Absensi Asisten Dosen Menggunakan QR Code Scanner Berbasis Android Pada Program Studi Sistem Informasi Universitas Muria Kudus." Prosiding SNATIF (2015): 303310.

Pujastuti, E., \& Laksito, A. D. (2020). Usability Testing on QR Code Scanner Application for Lecture Presence. Khazanah Informatika: Jurnal Ilmu Komputer dan Informatika, 6(1), 50-57.

Singh, A., \& Singh, P. (2016). A review: QR codes and its image pre-processing method. International Journal of Science, Engineering and Technology Research, 5(6), 1955-1960.

Singh, M., \& Garg, D. (2009, March). Choosing best hashing strategies and hash functions. In 2009 IEEE International Advance Computing Conference (pp. 50-55). IEEE.

Soon, T. J. (2008). QR code. Synthesis Journal, 2008, 59-78. 